\title{
Aplikasi 3D Mapping Menggunakan Virtual Reality (Studi Kasus Museum Sang Nila Utama)
}

\author{
Yoyon Efendi ${ }^{1}$, Junaidi ${ }^{2}$ \\ 1,2 Prodi Teknik Informarika STMIK Amik Riau \\ Jl. Purwodadi Indah Km. 10 Pekanbaru \\ yoyonefendi@stmik-amik-riau.ac.id, junaidi@stmik-amik-riau.ac.id
}

\begin{abstract}
Museum Sang Nila Utama is a cultural museum which has 3,819 collections covering geology, biology, ethnography, archeology, historica, numism, philology, ceramics, art and technologics. This museum as one of the cultural center and tourism of Riau Malay. Visitors are usually from schools and local tourists. Current museum visits are declining, leading to a lack of museum services and yet no creative strategies to improve it. Plus the thought that the museum is ancient, boring and unkempt. To handle the problem, it needs promotion media in the form of creative media based on technology. Besides, there is still a lack of promotion media in the introduction of museum cultural objects. One of the needs of interactive media applications and technology-based promotions. Applications as a Mobile-based promotional media with Virtual Reality $3 D$ objects tailored to the museum with various collections. This application uses research methods during the modeling process, VR, Mobile and users. This application is modeled using Blender and then processed its VR using Unity Engine. By making the Museum as one of tourist destination and culture of Riau Riau will bring many regional and foreign tourists. It is also to promote the calendar of Riau Province with the tagline "Riau Menyapa Dunia". With various destinations with various bases ranging from culture, history, religion and culinary typical of Riau.
\end{abstract}

Keywords: 3D, Virtual Reality, Mobile, Museum

\begin{abstract}
Abstrak
Museum Sang Nila Utama merupakan museum budaya yang mempunyai 3.819 koleksi yang meliputi geologika, biologika, etnografika, arkeologika, historika, numistika, filologika, keramologika, seni rupa dan teknologika. Museum ini sebagai salah pusat budaya dan pariwisata Melayu Riau. Pengunjung biasanya dari sekolah dan wisatawan lokal.Saat ini kunjungan museum menurun, disebabkan kurangnya layanan museum dan belum adanya strategi kreatif untuk meningkatkannya. Ditambah lagi adanya pemikiran bahwa museum sifatnya kuno, membosankan dan kurang terawat. Untuk menyelesaikan masalah itu, diperlukan media promosi dalam bentuk media kreatif berbasis teknologi. Disamping itu masih kurangnya media promosi dalam pengenalan benda-benda budaya museum. Salah satu caranya diperlukan media aplikasi interaktif dan promosi berbasis teknologi. Aplikasi sebagai media promosi berbasis Mobile dengan objek 3D Virtual Reality menggambarkan isi museum dengan berbagai koleksinya. Aplikasi ini menggunakan metode penelitian kerangka konseptual aplikasi melalui proses modelling, VR, Mobile dan pengguna. Aplikasi ini dibuat modelling dengan menggunakan Blender lalu diolah kembali VR nya menggunakan Unity Engine.Dengan adanya aplikasi ini akan menambah minat masyarakat dan meningkatkan kunjungan ke museum. Dengan menjadikan Museum sebagai salah satu destinasi wisata dan budaya Melayu Riau akan mendatangkan banyak wisatawan regional dan mancanegara. Ini juga mendukung kelender event pariwisata nasional dari Provinsi Riau dengan tagline "Riau Menyapa Dunia". Dengan berbagai destinasi dengan berbagai basis mulai dari budaya, sejarah, religi dan kuliner khas Riau.
\end{abstract}

Kata kunci: 3D, Virtual Reality, Mobile, Museum. 


\section{PENDAHULUAN}

Museum Sang Nila Utama merupakan salah satu wisata sejarah dan budaya di provinsi Riau. Museum ini mengumpulkan dan menyimpan warisan-warisan yang berhubungan dengan Riau-Budaya Melayu seperti pakaian adat pernikahan, permainan tradisional, instrument-instrumen musik dan artefak-artefak tradisional lainnya. Rendah nya pengunjung museum menjadi masalah besar yang harus di hadapi pengelola museum. Layanan yang masih bersifat manual memberikan keterbatasan petugas menjelaskan potensi museum secara keseluruhan. Akibatnya data koleksi museum tidak tersampaikan kepada pengunjung. Apalagi dengan koleksi yang belum tersusun secara baik dan benar serta penerangan yang belum memadai menambah kesan seram dan negatif akan museum.

Masalah yang lain, stigma masyarakat yang beranggapan bahwa mengunjugi museum hanya kegiatan membosankan dan kuno. Museum belum memiliki daya tarik yang menjadikan museum sebagai destinasi utama untuk dikunjungi dalam waktu senggang atau masa libur. Diperlukan media kreatif untuk meningkatkan jumlah pengunjung.Dari data museum, pengunjung masih di dominasi oleh anak-anak sekolah dan wisatawan lokal. Diperlukan alih teknologi menggunakan media interaksi dan promosi yang menarik bagi pengunjung museum. Salah satu media menggunakan teknologi Virtual Reality (VR) dengan objek 3 Dimensi. VR adalah teknologi berbasiskan komputer yang mengkombinasikan perangkat khusus input dan output agar pengguna dapat berinteraksi secara mendalam dengan lingkungan maya seolah-olah berada pada dunia nyata[1]. Aplikasi ini menggunakan blender untuk modelling 3D dan kompilasi VR menggunakan Unity. Proses selanjutnya buatkan apk (android package) lalu di instal ke smartphone. Cara penggunaanya pengunjung menjalankan apk lalu di pakaikan VR Boxnya. Android sebagai salah satu sistem operasi dalam perangkat Mobile.

Berkembangnya Mobile yang berbasis android dalam beberapa tahun ini orang-orang mengiginkan kemudahan untuk memperoleh sesuatu, perancangan aplikasi dengan platform android dapat menciptan aplikasi yang mudah diakses dan dapat memperoleh informasi-informasi yang diinginkan. platform android adalah untuk pengembang menciptakan aplikasi sendiri untuk digunakan berbagai bidang diantaranya aplikasi bidang wisata, aplikasi bidang pertanian, apliksi bidang kesehatan dan aplikasi game[2]. Dengan adanya peralihan teknologi secara Virtual Reality dapat mendukung minat pengunjung wisatawan lokal dan internasional ke museum. Tahun 2018 pihak museum menargetkan 50.000 pengunjung. Dengan berbagai macam obyek wisata, museum sang nila utama salah satu menjadi destinasi wisata edukasi dan budaya se Asia Tenggara apalagi dengan negara serumpun seperti Malaysia, Brunei dan Singapura. Hal ini sejalan tagline Provinsi Riau "Riau Menyapa Dunia”. 


\section{METODOLOGI PENELITIAN}

\subsection{Kerangka Konseptual Aplikasi}

Kerangka konseptual aplikasi merupakan pendeskripsian tentang rangkaian proses pada saat menggunakan aplikasi yang telah dibangun.

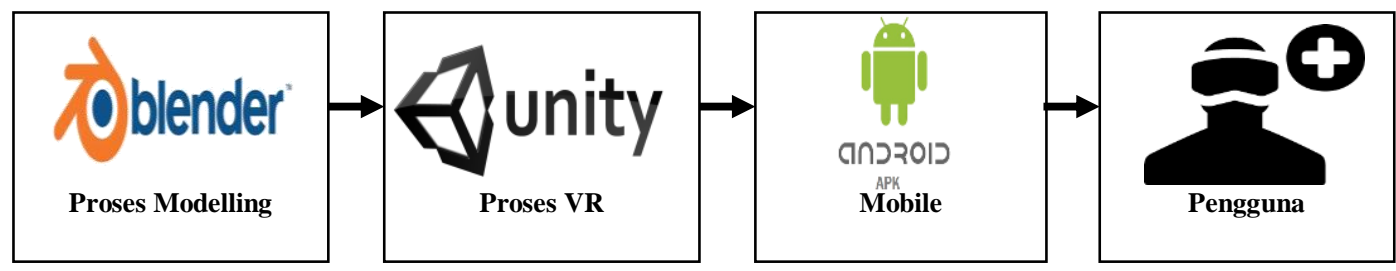

Gambar 1. Kerangka konseptual Aplikasi VR

Pada Gambar 1 aplikasi Blender digunakan untuk modelling bangunan dan benda museum dalam bentuk 3D. selanjutnya menggunakan game engine Unity untuk membuat aplikasi Virtual Reality lalu di export ke Android.apk yang dapat dijalankan pada perangkat Mobile (Smartphone) yang dipakai oleh pengguna.

\section{Modelling 3D (Blender)}

Blender adalah software modelling, rendering dan animasi tiga dimensi 3D yang kini menjadi primadona animator Indonesia dan seluruh dunia. Ukurannya yang (50 MB), kecepatan, kemudahan dan kelengkapannya bisa mengalahkan seniornya 3D Max dan Autodesk Maya. Selain modeling dan animasi 3D Blender juga bisa untuk video editing, video effects, image retouching, game development [3]. Proses modelling 3D menggunakan blender dimulai dari pemetaan museum lalu mengkonsep tata letak museum sesuai dengan bentuk aslinya. Proses modeling ini dapat dilihat pada gambar 2 sebagai berikut:

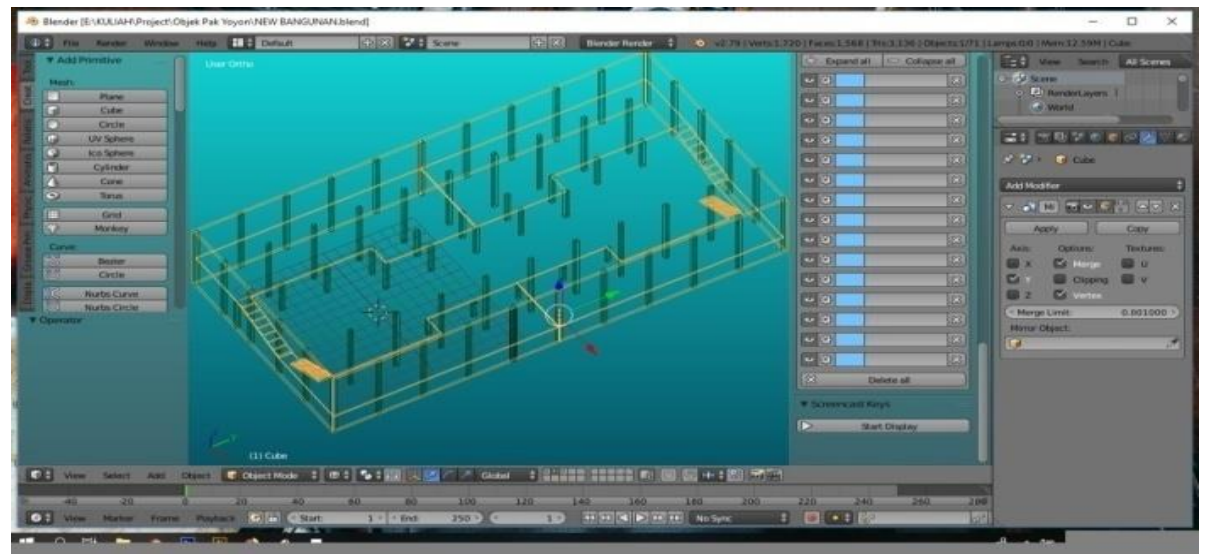

Gambar 2. Modelling 3D Pondasi museum pada blender

Proses modelling juga dapat dilihat saat modelling lemari museum seperti gambar 3 sebagai berikut: 


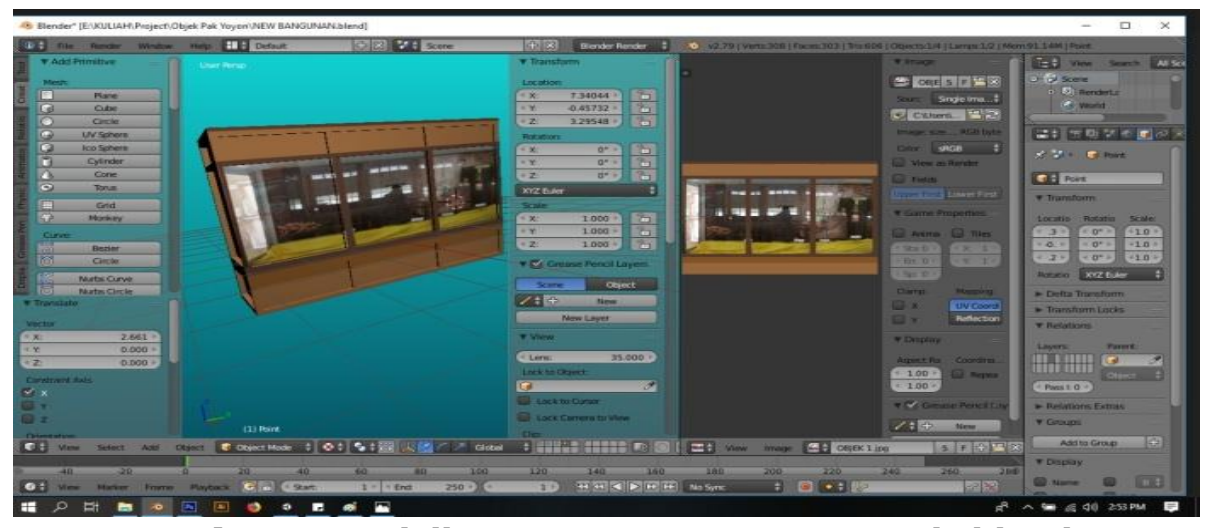

Gambar 3. Modelling 3D Lemari museum pada blender

Setelah semua proses modelling selesai lalu dilanjutkan proses render untuk melihat hasil tiga dimensi dari obyek atau benda-benda museum yang sudah dirancang tadi.

\section{Virtual Reality (Unity)}

Virtual Reality adalah simulasi komputer yang dihasilkan dari lingkungan tiga dimensi, yang tampaknya sangat nyata kepada orang yang pernah mencoba teknologinya. Tujuannya adalah untuk mencapai rasa yang kuat hadir di lingkungan virtual. Pengguna teknologi Virtual Reality menggunakan alatseperti kacamata untuk melihat adegan stereoscope tigadimensi. Pengguna dapat melihat sekitar dengan menggerakkan kepalanya dan berjalan-jalan dengan menggunakan kontrol tangan atau sensor gerak. Pengguna terlibat dalam suatu pengalaman yang seolah-olah ada di dunia virtual[4].

Setelah proses modelling lalu dilanjutkan ke proses Virtual Reality menggunakan 3D Engine Unity. Dapat dilihat peta museum di proses untuk dapat digunakan secara Virtual Reality seperti gambar 4 sebagai berikut:

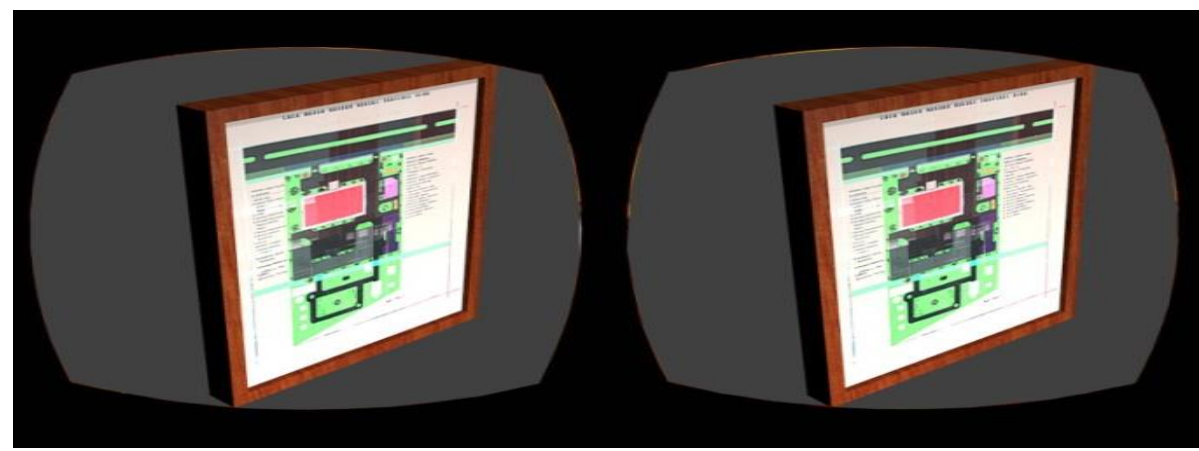

Gambar 4. Proses Vitual Reality peta museum pada unity

Proses Virtual Reality menggunakan unity juga dapat dilihat pada lemari museum gambar 5 sebagai berikut: 




Gambar 5. Proses Vitual Reality lemari museum pada unity

\section{Mobile}

Mobile adalah kata sifat yang berarti dapat bergerak atau dapat digerakkan dengan bebas dan mudah. Namun Mobile dapat pula diartikan sebuah benda yang berteknologi tinggi dan dapat bergerak tanpa menggunakan kabel. Contohnya seperti smartphone, PDA, dan tablet. Mobile juga bisa diartikan kendaraan bermotor yang dapat bergerak. Mobile bersifat bebas seperti air dan dapat mengalir kemanapun. Mobile dapat berubah dan diubah dengan mudah. Jadi ada gambaran awal tentang Mobile [5]. Perangkat Mobile biasanya menggunakan sisterm operasi android.

Android adalah sistem operasi untuk telepon seluler yang berbasis Linux. Android utamanya adalah produk Google, tetapi lebih tepatnya bagian dari Open Handset Alliance. Open Handset Alliance merupakan aliansi dari 30 organisasi yang berkomitmen untuk membawa sebuah perangkat seluler yang lebih baik dan terbuka untuk pasar. Android termasuk kernel berbasis Linux, aplikasi end-user, dan framework aplikasi. User application dibangun berbasiskan bahasa pemrograman Java. Bahkan aplikasi yang dibangun juga berbasiskan Java [6].

Setelah proses VR selesai dilanjutkan proses pembuatan apk (android package) agar bisa dijalankan pada sistem operasi android. Adapun rancangan perangkat Mobile (Smartphone) dapat dilihat pada gambar 6 sebagai berikut:

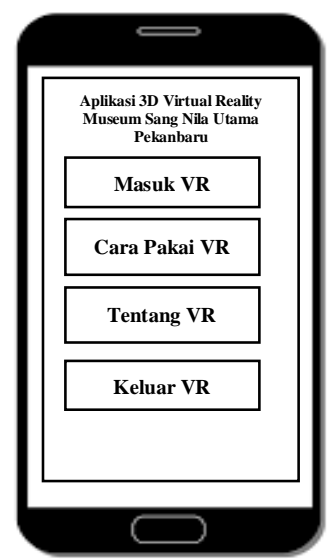

Gambar 6. VR Museum.Apk 


\section{Pengguna}

Pengguna menggunakan teknologi VR yang telah terinstall di smartphone dipasangkan ke VR Box seperti gambar 7 seperti berikut:

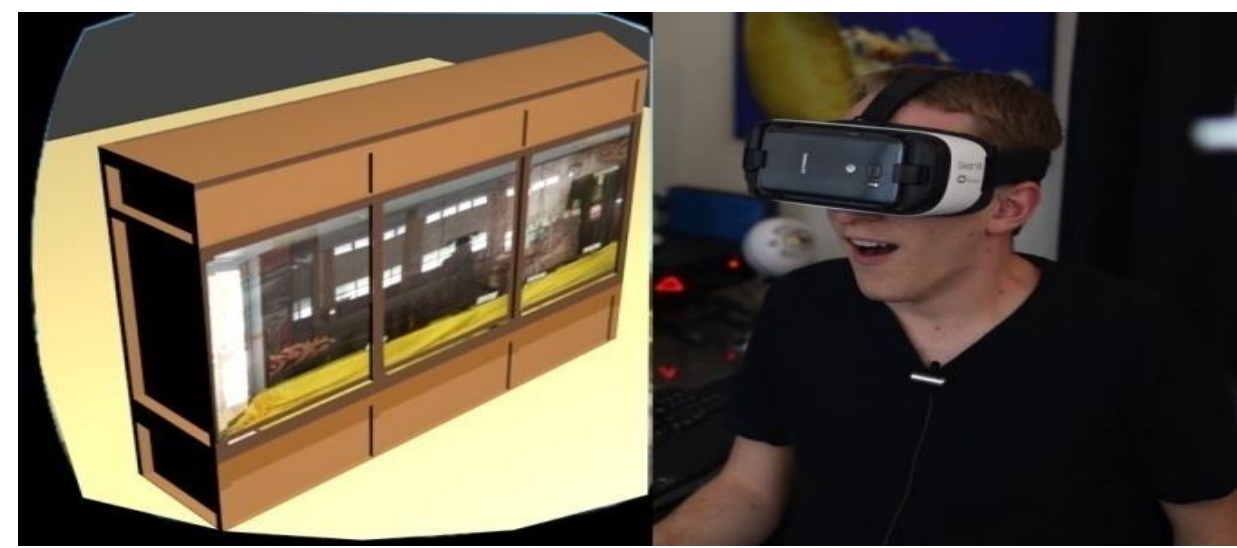

Gambar 7. Interaksi pengguna dengan 3D Virtual Reality

\section{HASIL DAN PEMBAHASAN}

\subsection{Interface Aplikasi Mobile}

a. Menu utama

Pada menu utama Mobile dapat dilihat beberapa menu yaitu Masuk VR, cara pakai VR, tentang VR dan keluar VR.

b. Menu masuk VR

Pada menu masuk VR dapat dilihat pengguna bisa langsung mengunakan aplikasi 3D Virtual Reality Museum Sang Nila Utama Pekanbaru. Berikut ini tampilan gambar menu utama dan menu masuk VR

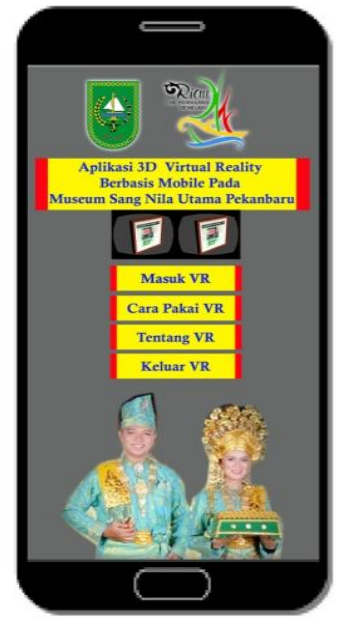

Gambar 8. menu utama

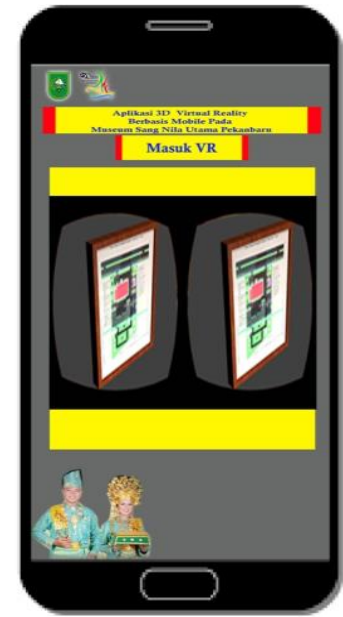

Gambar 9. menu masuk VR

Setelah masuk ke menu masuk VR, kita akan melihat mapping museum sang nila utama pekanbaru dengan bentuk 3 Dimensi (3D) seperti gambar 10 dibawah ini: 


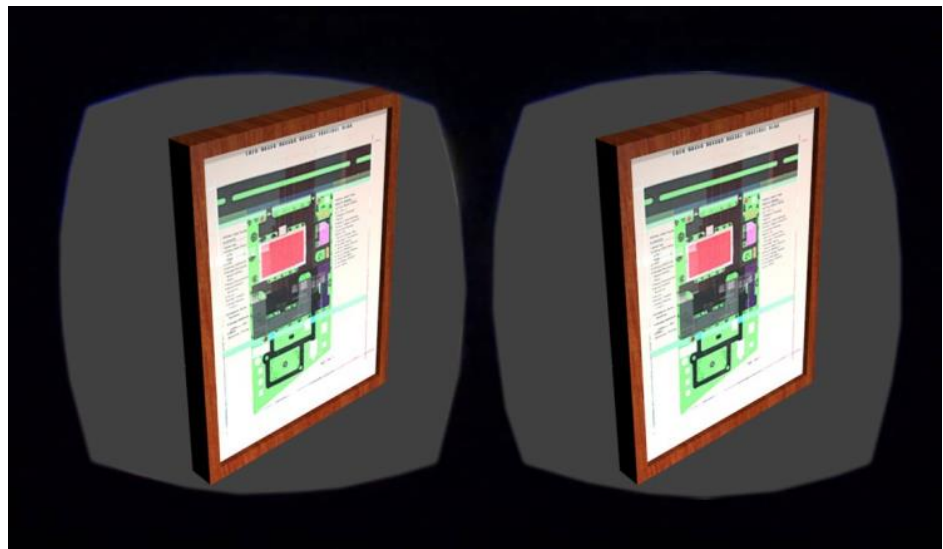

Gambar 10. 3D Mapping Museum pada VR

c. Menu cara pakai VR

Pada menu cara pakai VR dapat dilihat langkah-langkah pemakaian aplikasi ini oleh pengguna Museum Sang Nila Utama Pekanbaru.

d. Menu tentang VR

Pada menu tentang VR dapat dilihat dasar dan tujuan pembuatan aplikasi 3D Virtual Reality Museum Sang Nila Utama Pekanbaru.

e. Menu keluar VR

Pada menu keluar VR dapat dilihat pertanyaan yang akan diajukan kepada pengguna aplikasi 3D Virtual Reality Museum Sang Nila Utama Pekanbaru. Berikut ini tampilan dari menu cara pakai VR, menu tentang VR dan menu keluar VR

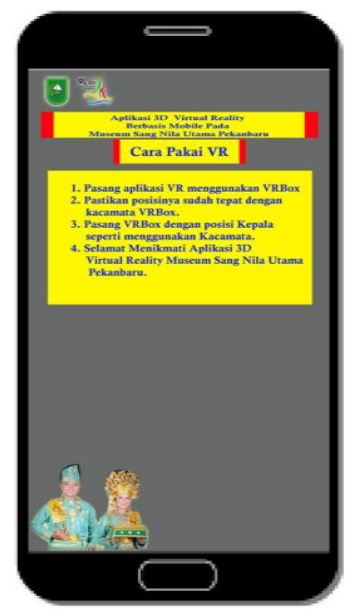

Gambar 11. menu cara pakai VR

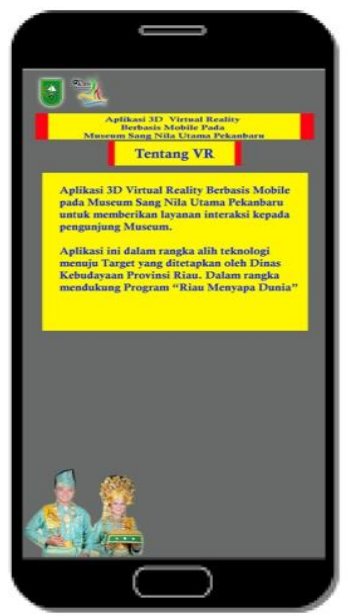

Gambar 12. menu tentang VR

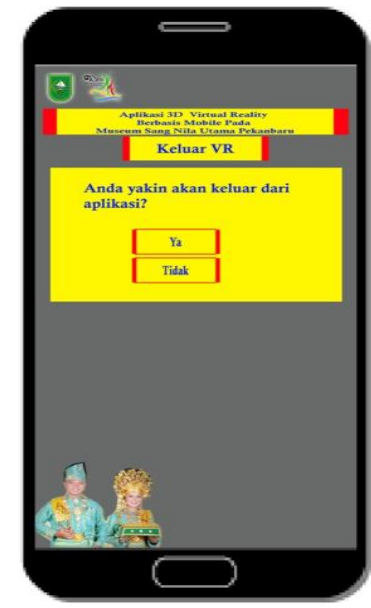

Gambar 13. menu keluar VR

\section{SIMPULAN}

Berdasarkan hasil penelitian pada aplikasi 3D Virtual Reality berbasis Mobile pada Museum Sang Nila Utama Pekanbaru dapat disimpulkan sebagai 
berikut: yang pertama Aplikasi ini sebagai media promosi interaktif kepada pengunjung museum. Kedua Aplikasi ini dapat menjadi daya tarik pengunjung terutama kawula muda seperti anak-anak sekolah. Ketiga Aplikasi ini membantu pihak museum dalam memberikan layanan kepada pengunjung.

Sedangkan saran dalam pengembangan penelitian ini yaitu Aplikasi ini dapat dikembangkan dengan menambah berbagai fitur- fitur kebudayan melayu Riau lainnya. Selain itu juga Aplikasi ini dapat di gunakan dengan berbagai sistem operasi seperti IOS dan lainnya

\section{DAFTAR PUSTAKA}

[1] Sulistyowati, "Pemanfaatan Teknologi 3D Virtual Reality Pada Pembelajaran Matematika Tingkat Sekolah Dasar," J. Ilm. NERO, vol. Volume 3, no. Nomor 1, p. Halaman 37-44, 2017.

[2] A. Rizki and R. Yulius, "PROSIDING seminar nasional sisfotek Sistem Informasi dan Teknologi Informasi Pemanfaatan Aplikasi berbasis Android Untuk Layanan Informasi Lokasi Stategis di Kota Payakumbuh," Pros. Semin. Nas. sisfotek, vol. 3584, pp. 157-161, 2017.

[3] F. S. Riyadi, "Aplikasi 3d virtual reality sebagai media pengenalan kampus politeknik negeri indramayu berbasis mobile," J. IInformatika dan Komputer(IIKO), vol. 2, no. 2, pp. 75-82, 2017.

[4] G. A. Putra, R. Kridalukmana, and K. T. Martono, "Pembuatan Simulasi 3D Virtual Reality Berbasis Android Sebagai Alat Bantu Terapi Acrophobia," J. Teknol. dan Sist. Komput., vol. 5, no. 1, p. 29, 2017.

[5] Y. Efendi, "Rancangan Aplikasi Game Edukasi Berbasis Mobile Menggunakan App Inventor," J. Indtra-Tech, vol. 2, no. 1, 2018.

[6] Y. Efendi, "Internet of Things ( Iot ) Sistem Pengendalian Lampu," J. Ilm. ilmu Komput., vol. 4, no. 1, pp. 19-26, 2018. 